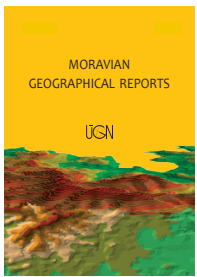

MORAVIAN GEOGRAPHICAL REPORTS

\title{
Intramax and other objective functions: The case of Slovenia
}

\author{
Samo DROBNE ${ }^{\text {a* }}$, Mitja LAKNER ${ }^{\text {a }}$
}

\begin{abstract}
The use of different objective functions in hierarchical aggregation procedures is examined in this paper. Specifically, we analyse the use of the original Intramax objective function, the sum-of-flows objective function, the sum-of-proportions-to-intra-regional-flows objective function, Smart's weighted interaction index, the first and second CURDS weighted interaction indices, and Tolbert and Killian's interaction index. The results of the functional regionalisation have been evaluated by self-containment statistics, and they show that the use of the original Intramax procedure tends to delineate operationally the most persuasive and balanced regions that, regarding the intra-regional flows, homogeneously cover the analysed territory. The other objective functions give statistically better but operationally less suitable results. Functional regions modelled using the original Intramax procedure were compared to the regions at NUTS 2 and NUTS 3 levels, as well as to administrative units in Slovenia. We conclude that there are some promising directions for further research on functional regionalisation using hierarchical aggregation procedures.
\end{abstract}

Keywords: Intramax, objective function, contiguity constraint, hierarchical aggregation, functional region, functional regionalisation, Slovenia

Article history: Received 4 November 2016; Accepted 4 June 2016; Published 30 June 2016

\section{Introduction}

The concept of the region has been traditionally one of the cornerstones of geographic thought. A region is a delimitated spatial system and an expression of organisational unity that differentiates it from another region (Abler et al., 1972; Gregory et al., 2009; Klapka et al., 2013). A functional region (FR) is a region organized by horizontal relations in a space in the form of spatial flows or interactions between parts of the region (Ullman, 1980), also called basic data units (BDUs) ${ }^{1}$. FR can be understood as a generalized pattern of spatial interactions. It can be defined by many different spatial interactions, including population flows (commuting to school or work, migration, shopping or recreation), traffic and goods flows (traffic and passenger flows by land/sea/air), commodity and financial flows, information flows (communications and newspaper circulation), gas/water/electricity flows (service connections), and so forth (Vanhove and Klaassen, 1987). In most of the literature, however, functional regions are defined by economic interactions. For example, Farmer and Fotheringham (2011) and Van der Laan and Schalke (2001) define a functional region as a spatially contiguous region in which aggregate supply and demand meet, and Karlsson and Olsson (2006) define a functional region as a territorial area characterised by a high frequency of intra-regional economic interactions (such as intra-regional trade in goods and services, labour commuting, and household shopping). Among different economic interactions, the daily interactions in the labour market are considered a good relative measure for the cohesion of a functional region (Ball, 1980; Cörvers et al., 2009; OECD, 2002). In this context, the basic characteristic of a functional region is the integrated labour market, in which intra-regional labour commuting, intra-regional job search, and search for labour demand are much more intensive than among the inter-regional counterparts (Karlsson and Olsson, 2006; Van der Laan and Schalke, 2001). Consequently, selfcontainment is the crucial characteristic of a functional region (Halás et al., 2015).

Several procedures for the delimitation of functional regions have been suggested (e.g. Coombes et al., 1986; Farmer, Fotheringham, 2011; Flórez-Revuelta et al., 2008;

\footnotetext{
${ }^{\text {a }}$ Department of Geodetic Engineering, Faculty of Civil and Geodetic Engineering, University of Ljubljana, Slovenia (*corresponding author: S. Drobne, e-mail: Samo.Drobne@fgg.uni-lj.si)
}

\footnotetext{
${ }^{1}$ Basic data units could be census units, statistical units, statistical local areas, settlements, communities, municipalities, postal zones, etc.
} 
Kim et al., 2015; Masser and Brown, 1975; Slater, 1981). Farmer and Fotheringham (2011) identified three general classes of functional regionalisation procedures: hierarchical aggregation, multistage aggregation, and central place aggregation. Regardless of the approach, the aim of regionalisation procedures is to define as many functional regions as possible, subject to certain statistical constraints that ensure that the regions remain statistically and operationally valid (Casado-Diaz and Coombes, 2011).

In this paper, we analyse systems of hierarchical FRs modelled by the hierarchical aggregation procedure used in the original Intramax objective function (Masser and Brown, 1975, 1977) and six other objective functions. Seven sets of systems of hierarchical FRs ${ }^{2}$ are analysed by well-known self-containment indicators (Goodman, 1970 Smart, 1974; Van der Laan and Schalke, 2001) and by the statistics suggested in this paper. The selected results of the hierarchical functional regionalisation are compared to regions at NUTS 2 and NUTS 3 levels and to administrative units (AUs) at LAU 1 level in Slovenia ${ }^{3}$.

This paper is organised as follows. In section 2, we discuss the development and implementation of the Intramax method. In section 3, we introduce a methodology for modelling and evaluating seven sets of systems of hierarchical FRs in Slovenia, and for comparing the selected systems of FRs to official regions at NUTS 2 and NUTS 3 levels, as well as to AUs in Slovenia. The results are presented and discussed in section 4 . Finally, section 5 concludes this topic of using different objective functions in the hierarchical aggregation procedure and suggests future research directions.

\section{Development and implementation of the Intramax method}

The Intramax method was developed by Masser and Brown (1975) for the purpose of analysing the structure of flows in a square interaction matrix (Brown and Pitfield, 1990). Masser and Brown (1977) emphasised two areas of the application of the Intramax procedure: the first of these was seen in dealing with the multi-level specification problem and with the association issue of data set reduction; and the second in functional regionalisation procedures. An example of the first application is the partitioning of a large interaction matrix into a number of spatially identifiable subsystems: "within each of which there is observed to be a high level of flows but between which flows are small and links are weak" (Brown and Pitfield, 1990: 60). Such principles are further discussed in Masser and Scheurwater (1978, 1980). The Intramax procedure was also suggested as a method of functional regionalisation (Masser and Brown, 1975). The results of such a regionalisation process are functional regions.
According to Masser and Brown (1975: 510): “... [in each aggregation step, the Intramax procedure seeks] to maximise the proportion of the total interaction which takes place within the aggregations of basic data units that form the diagonal elements of the matrix, and thereby to minimise the proportion of cross-boundary movements in the system as a whole". The authors reported, however, that the Intramax is a heuristic procedure which does not guarantee a global optimal solution to the partitioning problem (where maximum interaction flows would stay in the regions and less would cross the region's borders (Masser and Brown, 1977).

The incapability of the Intramax procedure to achieve a global optimal solution is mostly the consequence of the irreversibility of the aggregated BDUs/FRs (BDUs that are once aggregated in FR cannot be disaggregated any more). As reported many times (e.g. Alvanides et al., 2000; Casado-Diaz and Coombes, 2011; Coombes et al., 1986), the irreversibility of the aggregated BDUs/FRs is one of the most important shortcomings of the Intramax procedure, and a second problem is the indeterminacy of the number of FRs.

In its relative simplicity and its implementation in publicly available software ${ }^{4}$, however, one sees the reason that the Intramax method has been used so many times to analyse FRs - of so many different kinds of interactions at very different levels of consideration, for example: labour market area delineation (Masser and Scheurwater, 1980; Feldman et al., 2005; Watts, 2009; Landré, 2012; Landré and Híkansson, 2013; Koo, 2012); housing market area delineation (Goetgeluk and de Jong, 2007; Brown and Hincks, 2008; Jaegal, 2013); commodity market delineation (Brown and Pitfield, 1990); world trade block delineation (Poon, 1997; Kohl and Brouver, 2014); functional economic region delineation (Mitchell et al., 2007, 2013; Mitchell and Stimson, 2010; Mitchell and Watts, 2010); telecommunication analysis (Fischer et al., 1993); to identify possible administrative or statistical regions (Nel et al., 2008; Drobne and Bogataj, 2012a, 2012b); transport regions (Krygsman et al., 2009); in the (allocation) analysis of services (Drobne and Bogataj, 2014, 2015), and so forth.

In the Intramax procedure, which is a modified version of Ward's (1963) hierarchical aggregation procedure, two spatial BDUs that show the most intensive relative interaction (in terms of both of the flows) are joined together and stay fused for the remainder of the aggregation process, which continues until all BDUs are fused. Here, we consider interaction flows as entries in the interaction matrix $T=\left[t_{i j}\right]$, where $t_{i j} \geq 0$ is an observed value of the cell entry in the $i$-th row and the $j$-th column, namely the interaction flow from $B D U_{i}$ (origin $i$ ) to $B D U_{j}$ (destination $j$ ). So, the Intramax analysis is a stepwise analysis. In each step of the aggregation (hereinafter "aggregation step" or

\footnotetext{
2 In this paper, the term "system of hierarchical FRs" or, in short, "system of FRs", denotes delimitation of the analysed territory into FRs at each hierarchical level, but the term "set of systems of hierarchical FRs" or, in short, "set of systems of FRs" or "set of FRs", denotes all of the systems of hierarchical FRs modelled by an individual objective function.

${ }^{3}$ The NUTS (Nomenclature of Territorial Units for Statistics) classification is a hierarchical system for dividing up the economic territory of the EU for the purpose of: (a) the collection, development and harmonisation of EU regional statistics; (b) socioeconomic analyses of the regions; and (c) framing of EU regional policies (EC, 2003; 2007). In Slovenia, there is only one region at NUTS 0 or NUTS 1 level (the whole state), there are two regions at NUTS 2 level and 12 regions at NUTS 3 level. Below the NUTS levels, there are two LAU (Local Administrative Units) levels in Slovenia: the LAU 1 level defines 58 administrative units; and for the LAU 2 level 212 municipalities are defined in 2016.

${ }^{4}$ The Intramax procedure is implemented in Flowmap, which is a software package dedicated to analysing and displaying interaction or flow data developed at the Faculty of Geosciences of the Utrecht University in the Netherlands (De Jong and Van der Vaart, 2013).
} 
simply "step"), two BDUs/FRs ${ }^{5}$, whose interaction gives the highest value of the objective function, are grouped together, and the interaction between them becomes the internal (or intrazonal) interaction for the resulting FR. This new FR now takes the place of the two parent BDUs/FRs in the next step of the analysis. Thus, with $\mathrm{N}$ basic data units, all BDUs are grouped together into one FR after $\mathrm{N}-1$ steps and all interactions become intrazonal (Brown and Pitfield, 1990; Masser and Brown, 1975; Masser and Scheurwater, 1980; Nel et al., 2008). The procedure, as well as the results of the hierarchical aggregation, can be presented in a tree structure of a dendrogram.

In their first paper on the Intramax procedure, Masser and Brown (1975) specified the objective function as the difference between the observed values, $t_{i j}$, and expected values, $t_{i j}^{*}$ :

$$
\begin{aligned}
& F_{i j}=\left(t_{i j}-t_{i j}^{*}\right)+\left(t_{j i}-t_{j i}^{*}\right) \\
& \max _{i \neq j} F_{i j}
\end{aligned}
$$

where expected value $t_{i j}^{*}$ was calculated similarly to the expected frequency in the $i$-th row and the $j$-th column in a contingency table for the Chi-square test using the sum of the $i$-th row, $\mathrm{r}_{i}=\sum_{j} t_{i j}$, the sum of the $j$-th column, $c_{j}=\sum_{i} t_{i j}$, and the sum of all elements of matrix $T, t=\sum_{i, j} t_{i j}$ :

$$
t_{i j}^{*}=\frac{r_{i} c_{j}}{t}
$$

Note that when the objective function is defined as (1), matrix $T$ should be standardised by dividing $T$ by $t$, so that $T^{\prime}=\left[t_{i j}^{\prime}\right]$, where $\sum_{i, j} t_{i j}^{\prime}=1^{6}$. Masser and Brown (1975) applied the contiguity constraint, $\gamma_{i j}$, to restrict the search only for contiguous BDUs/FRs: $\gamma_{i j}=1$ when $B D U_{i} / \mathrm{FR}_{i}$ and $B D U_{j} / \mathrm{FR}_{j}$ are contiguous, and $\gamma_{i j}=0$ otherwise. They analysed the use of the objective function (1) using the commute-to-work data for Merseyside, England, and noted that, in practise, little or no difference may be expected in the results obtained with or without contiguity constraints and that the procedure would tend to favour small BDUs/ FRs (in the first place, small BDUs/FRs are aggregated, then large ones).

Following Tyree's findings (1973), Hirst (1977) noted that Masser and Brown (1975) took insufficient account of the influence that the row totals, $\mathrm{r}_{i}$, and column totals, $\mathrm{c}_{j}$, in $T=\left[t_{i j}\right]$ had on the residual values, $t_{i j}-t_{i j}^{*}$, that appeared in the objective function (1). The difference between the observed and expected values will tend to increase for cells (interactions) in those rows and columns with large sums (large outflows from BDUs/FRs and large inflows to BDUs/ FRs). Since the objective function is recalculated after each step in the grouping procedure, this bias will be cumulative. Using the methodological solutions for arbitrary origindestination distribution as defined by Goodman (1963), Hirst (1977) suggested that the effects of unequal marginal distribution could be overcome by reformulating the objective function in the revised version by dividing the difference $t_{i j}-t_{i j}^{*}$ by an expected value $t_{i j}^{*}$, with $t_{i j}^{*}$ corrected for $t_{i j}=0$ in $T$. Consequently Masser and Brown revised the objective function (Masser and Brown, 1977) as follows:

$$
F_{i j}=\frac{\left(t_{i j}-t_{i j}^{*}\right)}{t_{i j}^{*}}+\frac{\left(t_{j i}-t_{j i}^{*}\right)}{t_{j i}^{*}}
$$

The entries in the objective function (3) are not necessarily standardised. Hirst (1997) tested function (3) using hypothetical data. He noted that using the objective function (3) in the Intramax procedure would still tend to favour groupings of smaller BDUs/FRs before larger ones (because of the differences between the values obtained for small opposed to large BDUs/FRs).

Masser and Scheurwater (1978, 1980) first applied the revised version of the objective function (3) to real data, specifically the migration data on four contiguous zones within a larger dataset in Greater London, the migration data on forty regions from the Netherlands, and the labour commuting data for Merseyside that were used in the earlier paper on Intramax analysis (Masser and Brown, 1975). They concluded:

a. that the Intramax procedure "explicitly identifies regions that have more (direct) interaction with each other than with other areas at each stage of the grouping process" (Masser and Scheurwater, 1980: 1361);

b. that "the dendrogram obtained by the Intramax procedure has a well-developed tree structure in which basic data units combine to form broadly similar-sized clusters within the grouping process" (Masser and Scheurwater, 1978: 161);

c. that "stronger connections would appear between pairs of smaller zones containing a relatively low proportion of intrazonal interaction than between pairs of larger zones containing a relatively high proportion of intrazonal interaction, and that all other things being equal, the former would tend to fuse together before the latter" (Masser and Scheurwater, 1980: 1380);

d. that "the bias noted by Hirst (1977), far from being a disadvantage, is in fact a positive advantage in that it is a reflection of the inherent characteristics of the structure of spatial interaction in the matrix" (Masser and Scheurwater, 1980: 1380); and

e. that the Intramax procedure might be readily applied to large data sets and might be adapted easily to deal with large, sparse matrices (Masser and Brown, 1977; Masser and Scheurwater, 1980).

Brown and Pitfield (1990) noted that the part that was subtracted in (3) was a constant and might thus be ignored. So, the objective function (3) can be re-expressed more simply as follows (Brown and Pitfield, 1990):

$$
F_{i j}=\frac{t_{i j}}{t_{i j}^{*}}+\frac{t_{j i}}{t_{j i}^{*}}
$$

The objective function (4) is referred to as an original objective function of the Intramax procedure. The entries in (4) are not necessarily standardised.

Some recent methodological studies on using Intramax for functional regionalisation are discussed in the following

\footnotetext{
${ }^{5}$ Notation on BDUs/FRs: In the aggregation procedure, two BDUs, which are fused first, form a first FR. Thus, in the second step of the aggregation, two BDUs or one BDU and one FR can be fused; in the third step, two BDUs or one BDU and one FR or two FRs can be fused; and so on, until all BDUs are aggregated into FRs. From this step, from which no singleton region exists, small FRs are aggregated into larger ones.

${ }^{6}$ The results of the objective function (1) are dependent on the standardisation, because a proportional change of elements in the interaction matrix $T$ would not result in the same results as $T^{\prime}$.
} 
studies. Alvanides et al. (2000) analysed a set of systems of hierarchical FRs generated by the Intramax procedure and a set of systems of FRs modelled by ZDeSi (zone design system for interaction data; Openshaw and Rao, 1995; Openshaw and Alvanides, 1999) for 402 local authority districts in England and Wales using 1991 census data for labour commuting. The comparison of intra-regional flows showed the superiority of the ZDeSi model compared to the Intramax approach: the proportions of the intra-regional flows were higher for ZDeSi for all systems of FRs (more for systems of small FRs and less for systems of large FRs). It was reported also that it was evident from the results that "the Intramax procedure gets trapped in local optima, producing low scores and fragmented regions" (Alvanides et al., 2000: 127).

Watts (2009) evaluated hierarchical versus rule-based techniques of modelling FRs, namely the Intramax technique and the modified version of Coombes' updated algorithm (Coombes and Bond, 2008; Coombes, 2010), using the principles of fuzzy set theory (Feng, 2009), to explore the local properties of the two solutions. The application was carried out for 1,365 Australian statistical local areas and labour commuting data. He reported that both approaches to grouping had strong, but not robust, local optimisation properties (Watts, 2009). The robustness was analysed in relation to self-containment as defined by Smart (1974) and Van der Laan and Schalke (2001). Watts reported that "the low minimum rate of closure [of the Intramax method] underlines the point, however, that the grouping criterion under Intramax is quite different than those criteria characterising the Coombes algorithm. The number of groups in the final solution is more readily controlled under the Intramax technique, since the stopping rule can easily be adjusted to achieve a given form of final solution, which could be based on a minimum closure requirement, rather than the aggregate intrazonal flow. There may be limits as to the desirable rates of closure across groups. Otherwise convergence may be achieved with a singleton group, unless there is genuine geographical separation of the labour markets" (Watts, 2009: 525). He also noted the superiority of the Intramax method regarding the singleton regions.

Landre and Håkansson (2013) compared the performance of the Intramax procedure to the rule-based procedure used by Statistics Sweden's (2010) Local Labour Market Areas (LLMAs). The application was performed for 289 municipalities in Sweden. They reported that "although the procedure used for the construction of LLMAs differs considerably from that of Intramax regions, the results obtained are quite similar for most of the country ... Despite many similarities, the two methods differ fundamentally with regard to self-containment levels and the construction of regions in metropolitan areas. In the latter, Intramax analysis results in a fragmented pattern with unacceptable low levels of self-containment in a number of regions. However, LLMAs are clearly too large there" (Landre and Håkansson, 2013: 15). The same differences for the urban areas, where Intramax gives more fragmented FRs, have been reported by Feldman et al. (2005) for Scotland, and by Mitchell et al. (2007) for Australia. Landre and Híkansson concluded that "both methods could benefit from additional controls in their procedures, especially when applied in situations where differences in land area are large... for Intramax analysis, it could be the application of selfcontainment constraints resulting in the amalgamation of regions if these constraints are not met" (Landre and Håkansson, 2013: 15).
Koo (2012) suggested the use of a new objective function in the Intramax procedure that focused on the proportion of intra-regional flows,

$$
F_{i j}=\frac{t_{i j}}{t_{i i}}+\frac{t_{j i}}{t_{j j}},
$$

simultaneously with the use of a contiguity constraint and an area-balanced constraint. The algorithm was applied for the Seoul Metropolitan Area's data on labour commuting for a total of 1,180 BDUs. He reported that the "algorithm has derived a set of improved functional regions that better serves the objective of the regionalisation which maximises the proportion of internal flows more compared to Intramax" (Koo, 2012: 33). He noted that the constrained models gave better results than unconstrained ones with respect to the percentage of intra-regional flows. Koo also re-confirmed that the original Intramax model gave fragmented FRs in large urban areas.

Recently, Drobne and Lakner (2015, 2016) evaluated the simultaneous use of three different constraints in the Intramax procedure, namely: (a) the contiguity constraint; (b) the higher-proportion-of-intra-regionalflows constraint, which ensures that those regions are grouped together that gave a higher proportion of the intra-regional (inner) flows; and (c) the lower-coefficient-ofvariation-of-intra-regional-flows constraint, which ensures that a grouping of BDUs/FRs gives FRs with a similar (proportion) of intra-regional-flows. They noted that, when using data on labour commuting, there is no need to include the contiguity constraint in the procedure. They reported as well that the use of the higher-proportion-of-intraregional-flows constraint generates singleton regions, and that the lower-coefficient-of-variation-of-intra-regionalflows constraint forces the biggest BDU, as an isolated FR, up to a relatively high level of aggregation. They concluded that the Intramax procedure generates fragmented large urban areas, but the lower-coefficient-of-variation-of-intraregional-flows constraint even more strictly delineates the metropolitan area into fragmented pieces.

\section{Methodology}

The Intramax procedure is a stepwise (hierarchical aggregation) procedure. In each step, the two BDUs/FRs which the interaction realises the highest value of the objective function, are grouped together. In this paper, we analysed the performance when using different objective functions in the aggregation procedure. The performance was measured by known self-containment indicators, as well as by the self-containment statistics suggested in this paper. Selected systems of hierarchical FRs were compared to official regions at NUTS 2 and NUTS 3 levels, as well as to the administrative units (AUs) in Slovenia.

The application was done for the inter-municipal labour commuting flows in 2011 in Slovenia. The initial dimension of the interaction matrix $T$ was $N^{2}=210^{2}$. Of a total of 44,100 cells in the matrix, there were $31,557(71.56 \%)$ empty cells. In 2011, there were 778,776 labour commuters in total, but only 388,376 (49.87\%) of them commuted between municipalities. The rest $(390,400 ; 50.13 \%)$ formed intramunicipal flows. The maximum inflow of 109,884 (28.29\%) labour commuters terminated in the capital Ljubljana, which is the biggest employment centre of Slovenia, while the outflow from Ljubljana was 16,027 (4.13\%) of labour commuters. 
In the hierarchical aggregation procedure, we analysed the use of seven objective functions (see also Tab. 1 ): $\left(F_{1}\right)$ the original Intramax objective function, as defined by Brown and Pitfield (1990); $\left(F_{2}\right)$ the sum-of-flows objective function, which is the first logical alternative to the original objective function; it is also the only function analysed here that considers absolute values rather than proportions of flows; $\left(F_{3}\right)$ the sum-of-proportions-to-intra-regional-flows objective function, which is the revised version of the objective function suggested by Koo (2012), where only proportions of flows in the origins have been suggested, but, here, we suggest using the sum of all proportions of flows, namely in origins and in destinations; $\left(F_{4}\right)$ the first version of the CURDS weighted interaction index ${ }^{7}$, used for analysing Travel-To-Work-Areas (TTWA) in Great Britain (Coombes et al., 1982), which is a sum-of-proportions- to-out-/inflows objective function; $\left(F_{5}\right)$ Smart's weighted interaction index, which has been suggested on the ratio of gravity formula (Smart, 1974$)^{8} ;\left(F_{6}\right)$ the second version of the CURDS weighted interaction index, as defined by Coombes et al. (1986) and ONS and Coombes (1998) $)^{9}$; and $\left(F_{7}\right)$ Tolbert and Killian's interaction index (Tolbert and Killian, 1987; Killian and Tolbert, 1993), which aggregates two BDUs/FRs only if both flows of interaction are large ${ }^{10}$. Standardisation of the entries is not needed for any of the objective functions analysed here. For all functions $\left(F_{1}-F_{7}\right)$, we assume that all $t_{i i}>0$.

To analyse the performance of objective functions $F_{1}$ to $F_{7}$ and the use of the contiguity constraint in the Intramax procedure, we developed a programme code in Mathematica 10.3. To check the validity of contiguity,

\begin{tabular}{|c|c|c|c|}
\hline Id & Objective function & Description & Eq. \\
\hline$F_{1}$ & $F_{1 i j}=\frac{t_{i j}}{r_{i} c_{j}}+\frac{t_{j i}}{r_{j} c_{i}}=\frac{t_{i j}}{t_{i j}^{*}}+\frac{t_{j i}}{t_{j i}^{*}}$ & $\begin{array}{l}\text { Original Intramax objective function (Masser and } \\
\text { Brown, 1977; Brown and Pitfield, 1990) }\end{array}$ & (6) \\
\hline$F_{2}$ & $F_{2 i j}=t_{i j}+t_{j i}$ & Sum-of-flows objective function & (7) \\
\hline$F_{3}$ & $F_{3 i j}=\frac{t_{i j}}{t_{i i}}+\frac{t_{i j}}{t_{j j}}+\frac{t_{j i}}{t_{j j}}+\frac{t_{j i}}{t_{i i}}$ & $\begin{array}{l}\text { Sum-of-proportions-to-intra-regional-flows obje- } \\
\text { ctive function (compare to Koo, 2012) }\end{array}$ & (8) \\
\hline$F_{4}$ & $F_{4 i j}=\frac{t_{i j}}{r_{i}}+\frac{t_{i j}}{c_{j}}+\frac{t_{j i}}{r_{j}}+\frac{t_{j i}}{c_{i}}$ & $\begin{array}{l}\text { First version of CURDS weighted interaction in- } \\
\text { dex (Coombes et al., 1982) }\end{array}$ & (9) \\
\hline$F_{5}$ & $F_{5 i j}=\frac{t_{i j}}{t_{i i}} \frac{t_{i j}}{t_{j j}}+\frac{t_{j i}}{t_{j j}} \frac{t_{j i}}{t_{i i}}=\frac{t_{i j}^{2}+t_{j i}^{2}}{t_{i i} t_{j j}}$ & Smart's (1974) weighted interaction index & $(10)$ \\
\hline$F_{6}$ & $F_{6 i j}=\frac{t_{i j}}{r_{i}} \frac{t_{i j}}{c_{j}}+\frac{t_{j i}}{r_{j}} \frac{t_{j i}}{c_{i}}=\frac{t_{i j}^{2}}{r_{i} c_{j}}+\frac{t_{j i}^{2}}{r_{j} c_{i}}$ & $\begin{array}{l}\text { Second version of CURDS weighted interaction } \\
\text { index (Coombes et al., 1986) }\end{array}$ & $(11)$ \\
\hline$F_{7}$ & $F_{7 i j}=\frac{t_{i j}+t_{j i}}{\operatorname{Min}\left\{r_{i}, r_{j}\right\}}$ & Tolbert \& Killian's (1987) interaction index & $(12)$ \\
\hline
\end{tabular}

Tab. 1: Objective functions analysed in the hierarchical aggregation procedure

Source: As noted in the table and authors' elaboration

\footnotetext{
${ }^{7}$ CURDS: Centre for Urban \& Regional Development Studies in Newcastle University.

${ }^{8}$ Smart noted (1974: 270): "Where an area has a large absolute movement of workers to another area, this is represented in the numerator of the fraction by its square, ensuring that strong central pulls are not 'overlooked'. They are, however, balanced by the effect of the size of different areas on the denominator of the fraction, which acts as 'antibody' in the system preventing the emergence of the inflated labour markets [i.e. FRs]".

${ }^{9}$ Coombes and Bond (2008: 234) wrote that "considerable experimentation has led to the choice of the formula to determine in which way a zone should be grouped to maximise the likelihood that the resulting TTWA definitions most closely meet their objectives. The key need in practice is to enable smaller places near major centres to consolidate as separable TTWAs (where commuting flows justify this) because otherwise the TTWAs that include major centres expand remorselessly to engulf all surrounding areas, with the result that the set of defined TTWAs is less numerous than the maximum possible which meet the set criteria".

${ }^{10}$ As Tolbert and Killian (1987: 16) reported, "the numerator reflects a concern for the total number of commuters between two counties [BDUs] (regardless of direction) and as such, provides a measure of the degree of interconnectedness between them. The denominator expresses the volume of shared commuters on a relative rather than absolute basis, thus ensuring that the analysis is not dominated by large counties. The resident labour force ... is used as the base because it is not sensitive to the direction of commuting and because it is constant across all versions of frequency matrices". They emphasised the importance of using an asymmetric relationship: "The smaller county's resident labour force in the denominator ensures that even highly asymmetric commuting patterns are considered evidence of a strong labour market tie. Thus, while commuters from a small county may make up only a minor portion of a large county's labour force, those same commuters can represent a very substantial proportion of the smaller county's resident labour force. ... The counties clearly depend on each other in ways that have important social, economic, and political implications. Use of the large county's resident labour force or the sum of the two counties' labour forces would average the asymmetric relationship and reduce the apparent relationship between the two counties" (ibid.).
} 
we translated spatial contiguity into a network treegeneration problem. In this way, regions and their adjacency relationships are expressed as nodes and edges in a graph, so that a region is verified as contiguous only if there is at least one path connecting all the spatial units within the region or if all the spatial units within the region are connected to the tree structure (Kim et al., 2015). In our programme code, contiguity is checked by the depth-first search (DFS) algorithm (Daras, 2005).

Seven sets of systems of 2-209 FRs, generated in the hierarchical aggregation procedure using objective functions $F_{1}-F_{7}$, were evaluated at each stage of the aggregation procedure by self-containment indicators as suggested by Goodman (1970) and Smart (1974) and used very often in the literature (e.g. Casado-Diaz, 2000; CasadoDiaz and Coombes, 2011; Landré and Håkansson, 2013; Van der Laan in Schalke, 2001; Watts, 2009); namely, the proportion of intra-regional flows, supply-side selfcontainment (SSSC), and demand-side self-containment $(\mathrm{DSSC})^{11}$. The proportion of intra-regional (inner) flows was calculated as

$$
t_{i i}^{\%}=\frac{1}{t} \sum_{i} t_{i i}
$$

and supply-side self-containment (SSSC) and demand-side self-containment (DSSC) were calculated as follows:

$$
\begin{aligned}
S_{S S C} & =\frac{t_{i i}}{r_{i}}, \\
D_{S S C} & =\frac{t_{i i}}{c_{i}} .
\end{aligned}
$$

The basic property of the automatic hierarchical aggregation procedure should be the inclusion of all BDUs into FRs - without leaving any singleton regions. For this reason, we analysed the performance of objective functions also by the proportion of singleton regions, which was calculated as

$$
n_{s i}^{\%}=\frac{n_{s i}}{n},
$$

where $n_{s i}$ is the number of singletons, and $n$ is the total number of FRs (dimension of matrix T) at each step of aggregation.

Properties of different systems of FRs can be compared by absolute values like minimum, maximum, mean, and standard deviation of self-containment indicators. But, when comparing the homogeneity of FRs, relative statistics are the only valid approach to comparing the variation of self-containment of $\mathrm{FRs}^{12}$. In our study, we analysed the performance of using different objective functions in the hierarchical aggregation procedure to generate homogeneous FRs by relative self-containment indicators; namely by the coefficient of variation of SSSC and by the coefficient of variation of DSSC:

$$
\begin{aligned}
C V_{S S S C} & =\frac{\mu_{S S S C}}{\sigma_{S S S C}}, \\
C V_{D S S C} & =\frac{\mu_{D S S C}}{\sigma_{D S S C}},
\end{aligned}
$$

where $\mu_{S S S C}=\frac{1}{n} \sum_{i} S S S C_{i},, \sigma_{S S S C}=\sqrt{\frac{1}{n} \sum_{i}\left(S S S C_{i}-\mu_{S S S C}\right)^{2}}$, and $\mu_{D S S C}=\frac{1}{n} \sum_{i} D S S C_{i}, \sigma_{D S S C}=\sqrt{\frac{1}{n} \sum_{i}\left(D S S C_{i}-\mu_{D S S C}\right)^{2}}$.

We evaluated also the performance of objective functions $F_{1}-F_{7}$ to aggregate contiguous BDUs/FRs with the highest interactions when analysing labour commuting flows. As it has been shown several times (e.g. Brown and Pitfield, 1990; Drobne and Lakner, 2015, 2016; Feldman et al., 2005; Masser and Scheurwater, 1980), the inclusion of the contiguity constraint is, in general, not needed when analysing labour commuting flows in the original Intramax procedure. However, it should be considered when using a different objective function rather than the original one (Koo, 2012), in a combination with other constraints (Drobne and Lakner, 2015, 2016), or when analysing some other data (e.g. financial flows; Kohl and Brouver, 2014). When the contiguity constraint is used, two BDUs/FRs that give the maximal value of the analysed objective function are aggregated only if they are contiguous $\left(\gamma_{i j}=1\right)$. On the other hand, if the maximal value of the objective function is defined by two non-contiguous BDUs/FRs $\left(\gamma_{i j}=0\right)$, the contiguity constraint is used to seek the first contiguous BDUs/FRs. In this way, the constraint forces to aggregate two BDUs/FRs that do not provide the maximum value of the particular objective function. The sum of deviation from the maximum value of the objective function was measured by the sum of steps of seeking two contiguous BDUs/FRs (hereinafter "contiguity seeking steps", CSSs). The sum of deviation from the maximum value of the objective function, because of the contiguity constraint, measures the quality of the objective function to aggregate contiguous BDUs/FRs at a given interaction matrix. The inclusion of the contiguity constraint in the hierarchical aggregation procedure for a particular objective function is reported as $F_{1}^{(\gamma)}, F_{2}^{(\gamma)} \ldots F_{7}^{(\gamma)}$.

Following the basic objectives of the functional regionalisation by means of the hierarchical aggregation procedure, the most suitable systems of hierarchical FRs are defined by a relatively higher proportion of intra-regional flows $\left(t_{i i}^{\%}\right)$, by a relatively lower proportion of singleton regions $\left(n_{s i}^{\%}\right)$, by a lower coefficient of variation of supplyside self-containment $\left(\mathrm{CV}_{\mathrm{SSSC}}\right)$, by a lower coefficient of variation of demand-side self-containment $\left(\mathrm{CV}_{\mathrm{DSSC}}\right)$, and by a geographically valid spatial extent ${ }^{13}$. We evaluated efficiency of using different objective functions in the hierarchical aggregation procedure by ranks of $t_{i i}, n_{s i}^{\%}, \mathrm{CV}_{\mathrm{SSSC}}, \mathrm{CV}_{\mathrm{DSSC}}$, and CSS at each stage of the aggregation procedure. The general efficiency for each objective function is calculated as a mean of ranks. The performance of the analysed objective functions was evaluated also by dendrograms

\footnotetext{
${ }^{11}$ In the analysis of labour commuting (journey-to-work) flows, supply-side self-containment (SSSC) is also called workplacebased self-containment (Goodman, 1970; Smart, 1974) or employment self-containment (Van der Laan and Schalke, 2001); similarly, demand-side self-containment (DSSC) is also called residence-based self-containment (Goodman, 1970; Smart, 1974) or housing self-containment (Van der Laan and Schalke, 2001).

12 Systems of FRs modelled by different methods represent different populations. When comparing the variation of selfcontainment of FRs, only relative values should be used. However, there are many reports on standard deviation (absolute value) of self-containment in the literature (e.g. Casado-Diaz, 2000; Landre and Håkansson, 2013; Watts, 2009), but, unfortunately, there is no notion on relative statistics (e.g. coefficient of variation)

${ }^{13}$ Regarding geography, FRs of most of the interactions mentioned here (particularly of commuting and migration) should be geographically compact; however, there are some exceptions, like trade FRs.
} 
and by animations of the hierarchical aggregation of BDUs into FRs, which were generated by our programme code in Mathematica 10.3

The properties of FRs modelled in the original Intramax procedure were then compared to the current regions at NUTS 2 and NUTS 3 levels and administrative units in Slovenia. In Slovenia, there are 2 regions for the application of regional policies at NUTS 2 level also called "macro regions" or "cohesion regions", and there are 12 "statistical regions" at NUTS 3 level also called "development regions". Below the NUTS 3 level in Slovenia, there is the LAU 1 level where 58 "administrative units" are defined.

\section{Results and discussion}

First, we represent and discuss the results of the hierarchical aggregation procedure regarding different objective functions without the use of the contiguity constraint. Fig. 1 shows the results with respect to intraregional flows, singleton regions, and the homogeneity of supply-side and demand-side self-containment of the hierarchical FRs. Comparing the performance of objective functions regarding the proportion of intra-regional flows (Fig. 1a), the superiority of $F_{2}$ and the inferiority of $F_{1}$ are obvious. From other objective functions, good results were obtained by the use of $F_{7}$ and $F_{4}$ for the regionalisation at the beginning of the aggregation procedure, but for the use of $F_{6}$ good results were found only at the end of the procedure.

Regarding the number of singleton regions, the results of using $F_{1}$ and $F_{2}$ are opposite of that for intra-regional flows (compare Fig. 1a and Fig. 1b). The most effective objective function at all aggregation levels that aggregates singletons is original Intramax function $F_{1}$. It starts to aggregate small BDUs first and leaves the most important destination BDU in Slovenia, i.e. the capital of Ljubljana, as a singleton region up to the last $10 \%$ of the aggregation steps (ASs). But, $F_{2}$ chains neighbouring BDUs to Ljubljana. So, the number (proportion) of remaining singletons is the highest for all stages of aggregation when using the sumof-flows function $F_{2}$. Among other objective functions, at the beginning of the aggregation procedure, $F_{5}$ and $F_{6}$ reduce the number of singletons fast, but they miss some of them for the rest of the steps. $F_{3}$ and $F_{4}$ produce very similar results, aggregating singletons much earlier than $F_{7}$. Among the functions that solve the problem of aggregating small BDUs (and not leaving singletons), $F_{1}$ performs the best, as it aggregates the last singletons in the $190^{\text {th }}$ AS; the next-best functions are $F_{3}$ and $F_{4}$, which aggregate the last singletons in the $191^{\text {st }}$ and $192^{\text {nd }} \mathrm{AS}$, respectively, whereas $F_{7}$ aggregates them in the $196^{\text {th }}$ AS. However, $F_{1}$ performs quite differently from the other functions, as it leaves the bigger BDUs as separate FRs to compete with other FRs, whereas $F_{3}, F_{4}$, and $F_{7}$ produce singletons that cannot compete with other FRs at each stage of the aggregation procedure (in our case, singleton regions were different borderline municipalities whose inferiority was evident at each step before they were aggregated into FRs).

The hierarchical aggregation procedure should produce systems of homogeneously self-contained FRs with the smallest possible variation of supply-side and demand-side self-containment. Here, $F_{3}$ and $F_{4}$ give the best results for almost the whole procedure of the aggregation. $F_{1}$ is better only for the last steps of the aggregation, when modelling just $2-5$ FRs. $F_{5}$ is also competitive, but only at the beginning and at the end of the aggregation procedure. The most dissimilar FRs regarding the self-containment of flows were obtained using $F_{2}$ and $F_{6}$. Comparison of homogeneity of selfcontainment of $\mathrm{FRs}$ generated by different objective functions shows also that, among the objective functions analysed here,

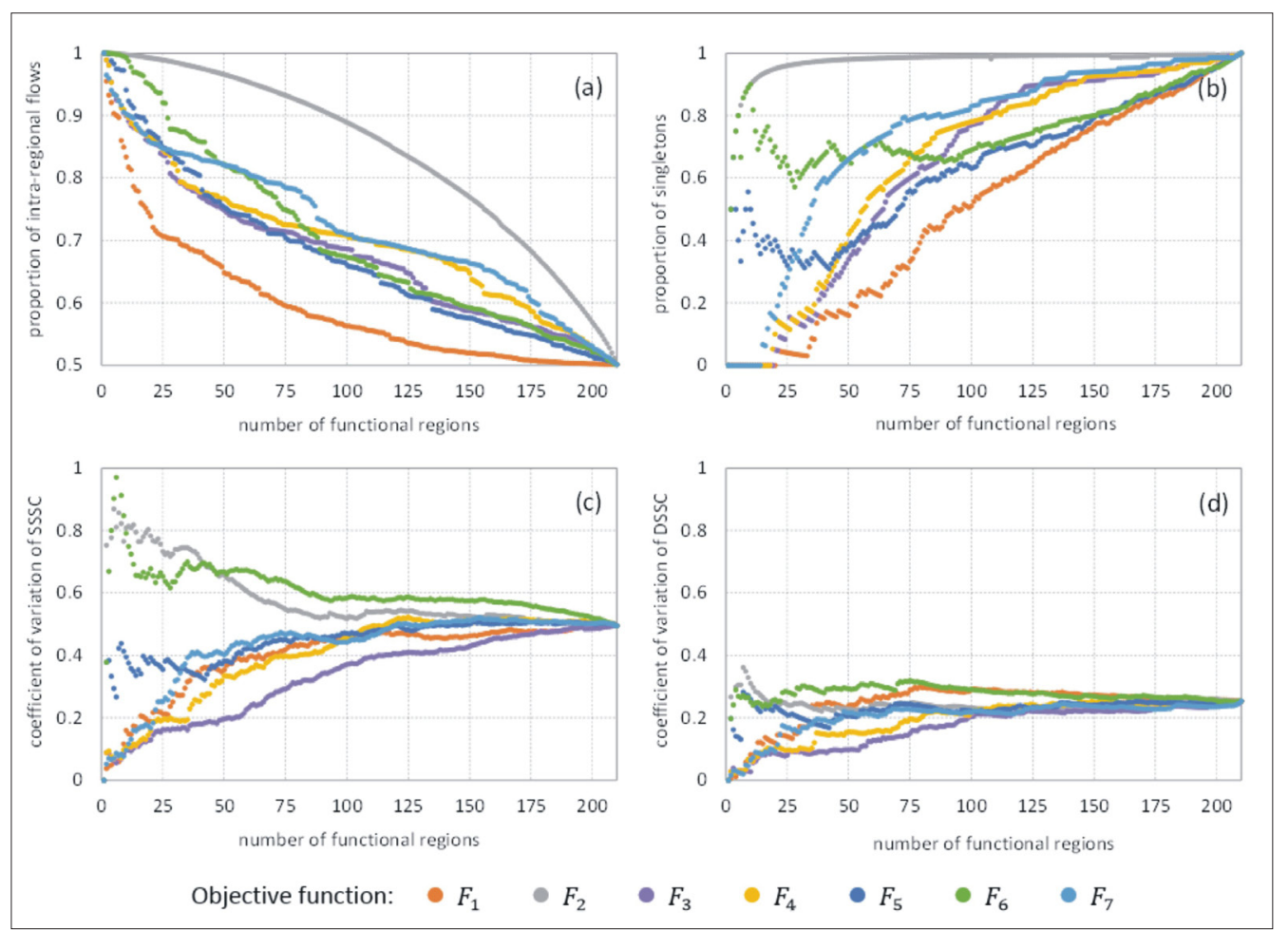

Fig. 1: (a) Proportion of intra-regional flows, (b) proportion of singleton regions, (c) coefficient of variation of supplyside self-containment, and (d) coefficient of variation of demand-side self-containment, hierarchical aggregation of municipalities regarding the labour commuting flows without the continuity constraint (Slovenia, 2011)

Source: authors' calculations 
the original Intramax objective function performs better, in general, regarding the supply-side self-containment than regarding the demand-side self-containment.

The performance of using the individual objective function in the hierarchical aggregation procedure can also be expressed by the capability to aggregate contiguous BDUs at a given interaction matrix. Such a capability of the analysed objective functions for data on labour commuting between Slovene municipalities in 2011 was measured by the sum of deviations from the maximum value of the objective function, namely, contiguity seeking steps, CSSs; see Fig. 2 where frequency distribution of CCSs is represented. Here, $F_{2}{ }^{(\gamma)}$, which forced almost $490 \mathrm{CCSs}$ in total, was the least effective objective function among all the analysed objective functions. It was followed by $F_{3}{ }^{(\gamma)}$ with more than $150 \mathrm{CSSs}$, by $F_{7}{ }^{(\gamma)}$ with more than $50 \mathrm{CSSs}$, and by $F_{5}{ }^{(\gamma)}$ with $12 \mathrm{CSSs}$. Objective functions $F_{1}{ }^{(\gamma)}, F_{4}{ }^{(\gamma)}$, and $F_{6}{ }^{(\gamma)}$ are very effective objective functions while they aggregated mostly contiguous BDUs/FRs: $F_{4}{ }^{(\gamma)}$ forced only $3 \mathrm{CSSs}, F_{6}{ }^{(\gamma)}$ only $2 \mathrm{CSSs}$, and $F_{1}{ }^{(\gamma)}$ only $1 \mathrm{CSS}$.

From the aforementioned results of the comparative analysis of using vs. omitting the contiguity constraint and from Fig. 2, we summarise that the use of the contiguity constraint is not needed when modelling bigger labour commuting FRs (in our case 2 to $20 \mathrm{FRs}$ ) - this is valid for the use of all analysed objective functions. Especially when using the objective function that considers variations in all rows and columns in the interaction matrix - like the original Intramax function $\left(F_{1}\right)$ or the first $\left(F_{4}\right)$ and the second CURDS's weighted interaction function $\left(F_{6}\right)$ - the results of modelling FRs are similar when using or omitting the contiguity constraint.

The evaluation of using different objective functions in the hierarchical aggregation procedure by ranks of intraregional flows, proportion of singleton regions, coefficient of variation of supply-side self-containment, coefficient of variation of demand-side self-containment, and contiguity seeking steps that were calculated at each aggregation stage showed that, in general, $F_{3}, F_{4}, F_{5}$, and $F_{7}$ generate statistically better results than original Intramax objective function $F_{1}$; see Fig. 3 . According to the general evaluation of statistical results, $F_{2}$ and $F_{6}$ are the only objective functions whose efficiency is statistically worse than that of using $F_{1}$. However, geographic and operational evaluation of systems of hierarchical FRs by dendrograms and by animations of the

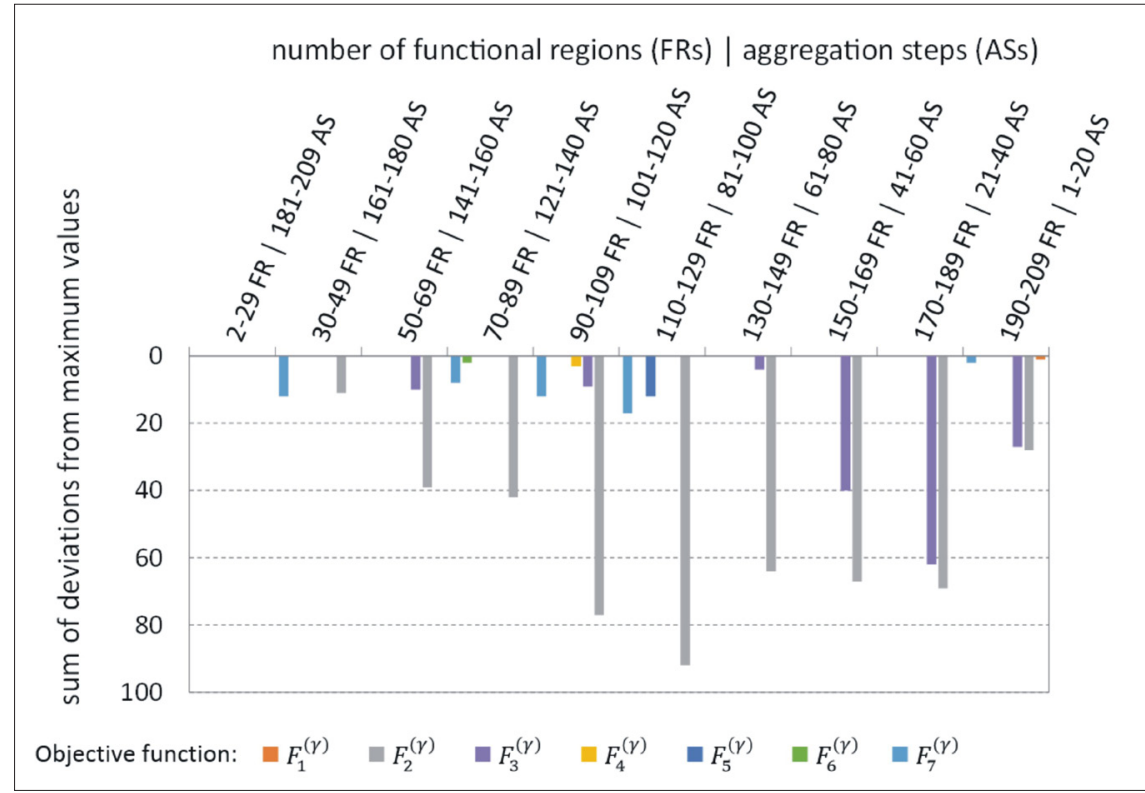

Fig. 2: Sum of deviations from maximum values of the objective function because of the contiguity constraint (Slovenia, 2011). Source: authors' calculations

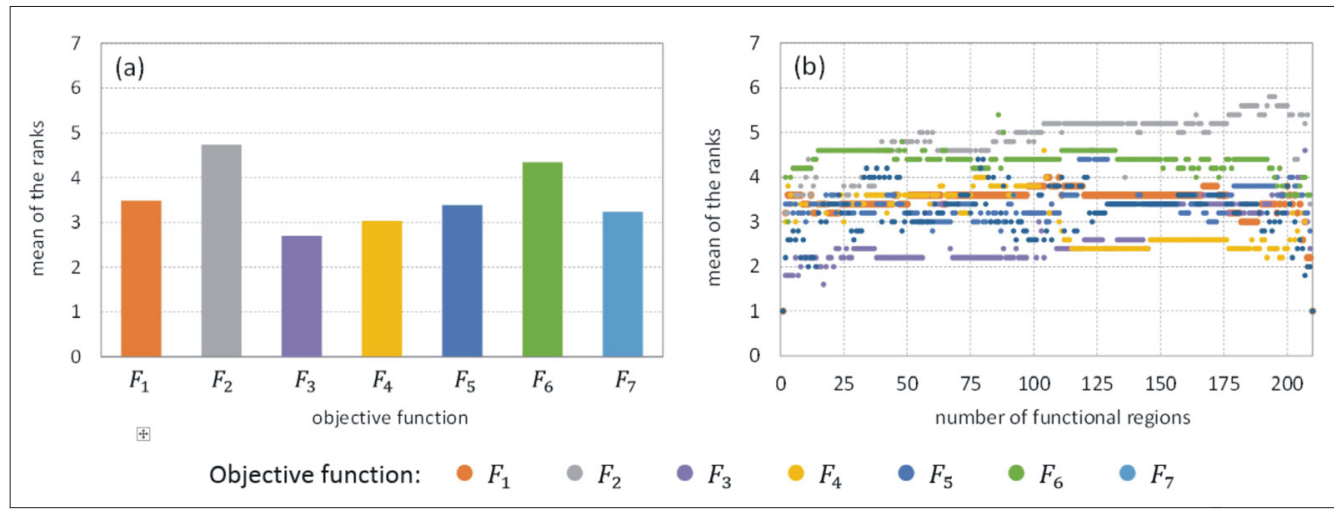

Fig. 3: General evaluation of sets of hierarchical functional regions modelled using objective functions $F_{1}-F_{7}$ by ranks of the analysed indicators: (a) mean of the ranks in the set of systems of functional regions, (b) mean of the ranks by systems of functional regions, hierarchical aggregation of municipalities regarding the labour commuting flows without the use of the contiguity constraint (Slovenia, 2011). Source: authors' calculations Note: A lower value indicates better ranking 
aggregation of municipalities showed that the most suitable FRs were generated using the original Intramax procedure. Besides the original Intramax objective function, Smart's weighted interaction index models also persuasive labour commuting FRs (if singletons are corrected manually).

The efficiency of FRs modelled by the original Intramax procedure was analysed also by comparison to the delimitation of Slovenian territory into 2 "cohesion regions" at the NUTS 2 level (see Fig. 4), into 12 "statistical regions" at NUTS 3 level (see Fig. 5), and into 58 administrative units of Slovenia at LAU 1 level (see Fig. 6). While the cohesion regions have existed only since 2008, the first version of statistical regions dates back to the mid-1970s. At that time, statistical regions were established for the purpose of regional planning and cooperation in various sectors. The first regionalisation of statistical regions was supported by exhaustive gravity analysis of labour markets, education areas, and supply markets in twelve regional, and their sub-regional, centres. Up to 2011, statistical regions were fine-tuned several times - that is the reason why today's

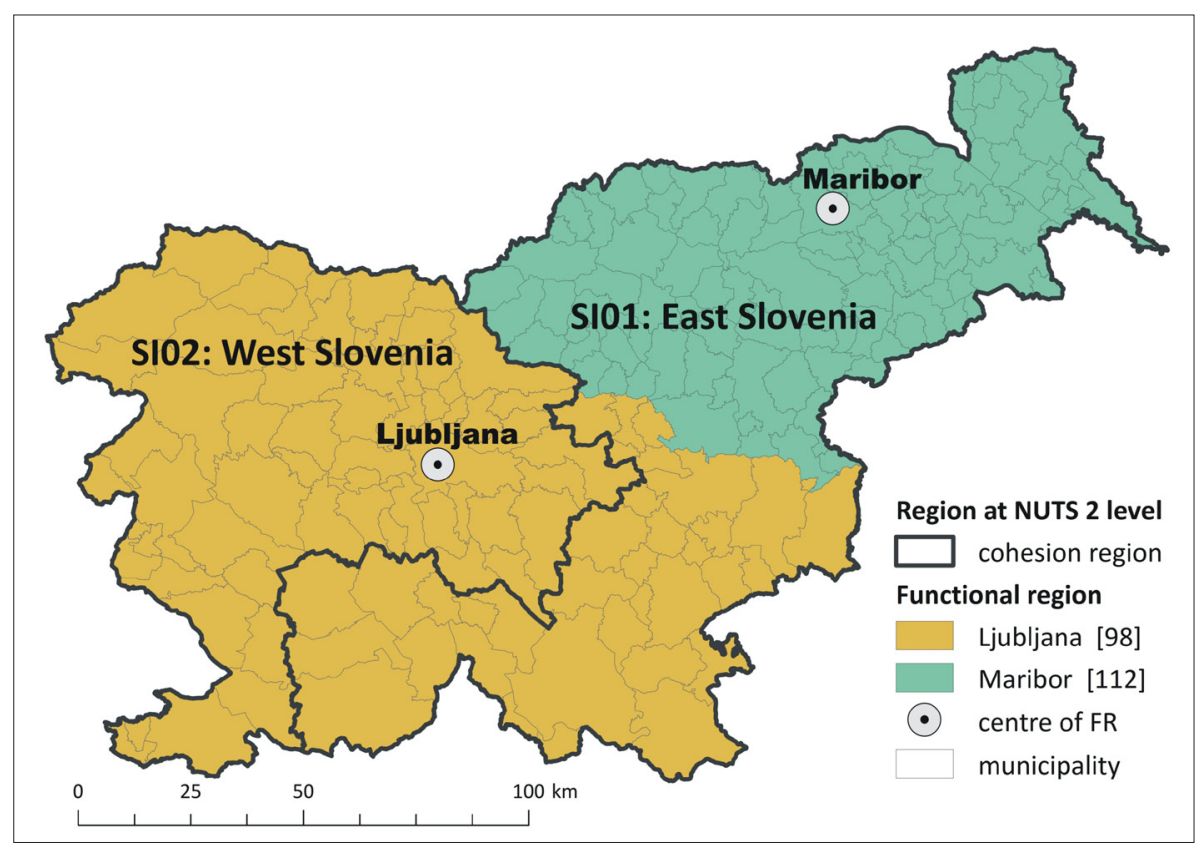

Fig. 4: Two regions at NUTS 2 level and two functional regions modelled by original Intramax procedure (Slovenia, 2011). Source: authors' calculations

Notes: The number of the municipalities in the FR is given in square bracket. In 2011, there were 210 municipalities in Slovenia.

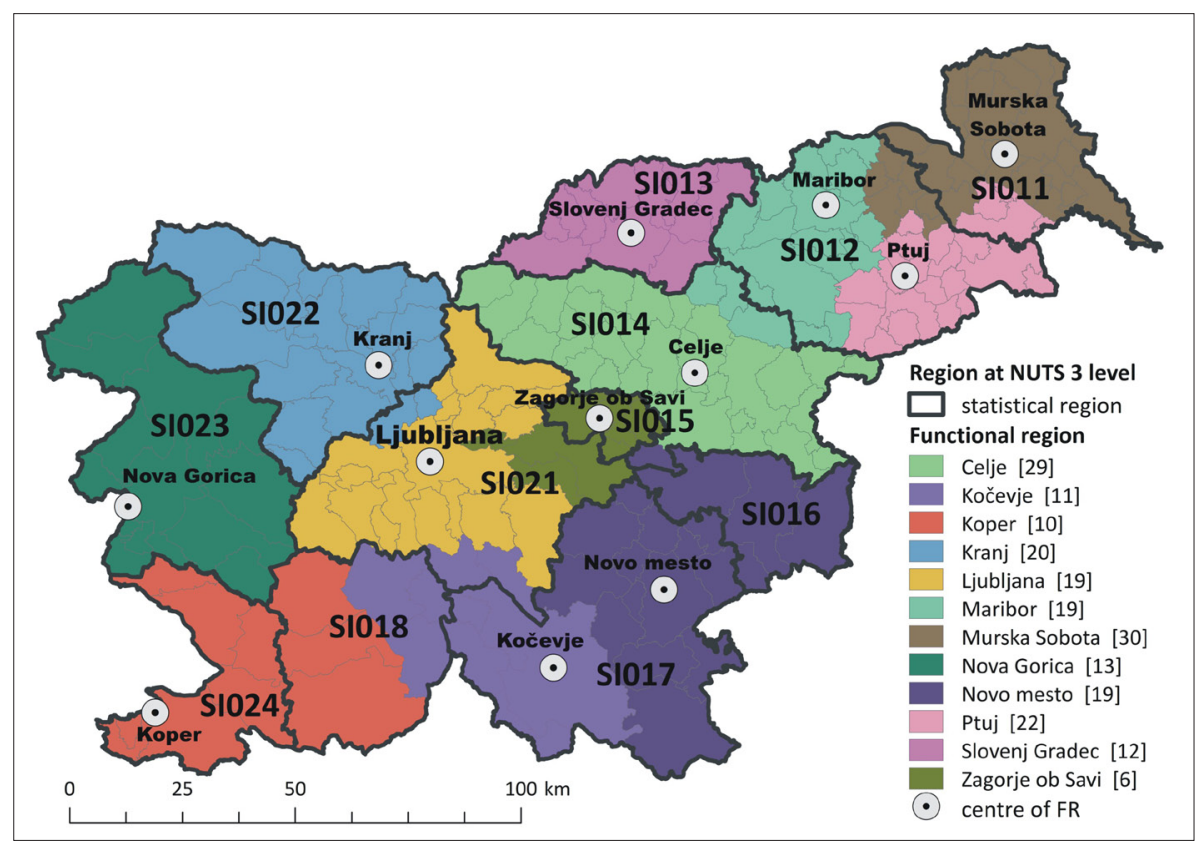

Fig. 5: 12 statistical regions at NUTS 3 level and 12 functional regions modelled by original Intramax procedure (Slovenia, 2011). Source: authors' calculations

Notes: Regions at NUTS 3 level are: Pomurska (SI011), Podravska (SI012), Koroška (SI013), Savinjska (SI014), Zasavska (SI015), Posavska (SI016), South-East Slovenia (SI017), Primorsko-notranjska (SI018), Central Slovenia (SI021), Gorenjska (SI022), Goriška (SI023), and Obalno-kraška (SI024). The number of the municipalities in the FR is given in square brackets. In 2011, there were 210 municipalities in Slovenia 
Slovenian regions at NUTS 3 level are very stable (Drobne and Bogataj, 2012a; SORS, 2016). Some 58 administrative units were set up in 1991 to optimise administrative tasks between citizens and state. They were delimitated on the base of 62 old municipalities that were transformed into much smaller ones (147) in 1994. From that time, municipalities in Slovenia were changed several times to the 212 municipalities existing in 2016.

The comparison of FRs to official regions and administrative units showed that 12 statistical regions and 58 administrative units, which were delimitated on the long-term bases of functional interactions in Slovenian territory, demonstrated higher self-containment than the corresponding number of FRs. From Tab. 2, it is evident that the proportion of intra-regional flows at the state level is higher, as well as the homogeneity regarding intra-regional flows, supply-side and demand-side self-containment for statistical regions and administrative units, than for FRs modelled using the original Intramax procedure.

But, both cohesion regions at NUTS 2 level, which were established for the application of regional policies, demonstrate lower self-containment than FRs. Among others, the reason for that is rooted in Slovenian tradition. In older European Union member countries, administrative regions are the units in which regional economic policies are designed and executed and the members of regional

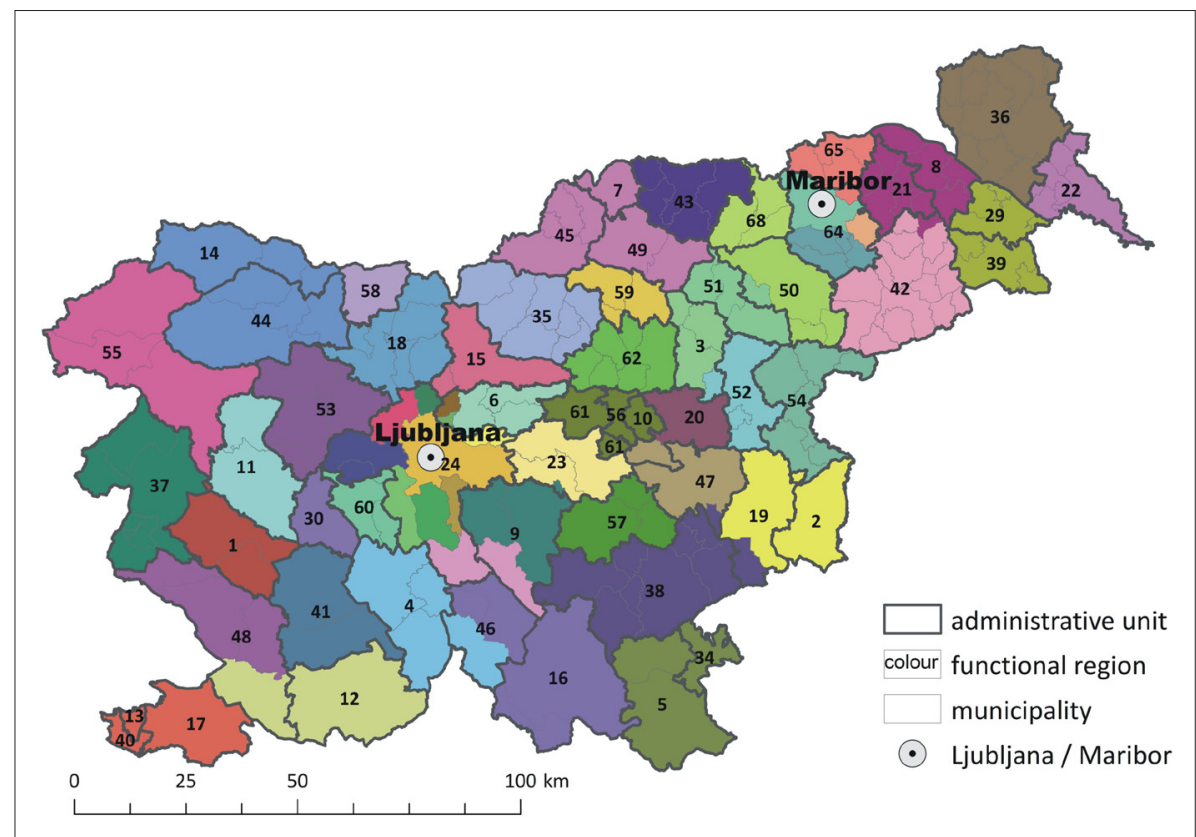

Fig. 6: 58 administrative units at LAU 1 level and 58 functional regions modelled by original Intramax procedure (Slovenia, 2011). Source: authors' calculations

Notes: The maps indicates the codes for administrative units. The list of 58 administrative units is available at http://www.upravneenote.gov.si/. In 2011, there were 210 municipalities in Slovenia

\begin{tabular}{ccccccc}
\hline & $\begin{array}{c}\text { 2 NUTS 2 } \\
\text { (cohesion) } \\
\text { regions }\end{array}$ & 2 FRs & $\begin{array}{c}\text { 12 NUTS 3 } \\
\text { (statistical) } \\
\text { regions }\end{array}$ & 12 FRs & 58 AUs & 58 FRs \\
\hline $\begin{array}{c}T_{i i} \text { or } S S S C \text { or } D S S C \\
\text { at state level }\end{array}$ & $92.0 \%$ & $95.5 \%$ & $83.7 \%$ & $81.3 \%$ & $64.5 \%$ & $63.4 \%$ \\
\hline$C V_{T_{i i}}$ & 0.053 & 0.038 & 0.124 & 0.147 & 0.240 & 0.388 \\
$\operatorname{Min}_{T_{i i}}$ & $87.2 \%$ & $90.9 \%$ & $59.5 \%$ & $51.5 \%$ & $29.9 \%$ & $17.0 \%$ \\
$\operatorname{Max}_{i i}$ & $97.0 \%$ & $98.1 \%$ & $92.7 \%$ & $91.9 \%$ & $86.9 \%$ & $85.4 \%$ \\
\hline$V_{S S S C}$ & 0.053 & 0.038 & 0.124 & 0.147 & 0.240 & 0.388 \\
$\operatorname{Min}_{S S S C}$ & $87.2 \%$ & $90.9 \%$ & $59.5 \%$ & $51.5 \%$ & $29.9 \%$ & $17.0 \%$ \\
$\operatorname{Max}_{S S S C}$ & $97.0 \%$ & $98.1 \%$ & $92.7 \%$ & $91.9 \%$ & $86.9 \%$ & $85.4 \%$ \\
\hline$C V_{D S S C}$ & 0.047 & 0.006 & 0.057 & 0.075 & 0.140 & 0.254 \\
$\operatorname{Min}_{D S S C}$ & $88.0 \%$ & $95.1 \%$ & $73.9 \%$ & $68.6 \%$ & $45.1 \%$ & $6.7 \%$ \\
$\operatorname{Max}_{D S S C}$ & $96.7 \%$ & $96.3 \%$ & $94.0 \%$ & $94.0 \%$ & $89.7 \%$ & $89.7 \%$ \\
\hline
\end{tabular}

Tab. 2: Comparison of functional regions in 2011 to the delimitation of the Slovenian territory at NUTS 2 and NUTS 3 levels and to administrative units (Slovenia, 2011). Source: authors' elaboration

Notes: FR denotes functional region, $T_{i i}$ denotes intra-regional flow, SSSC is supply-side self-containment, DSSC is demand-side self-containment, $C V$ is coefficient of variation, Min denotes minimum, and Max denotes maximum 
governments and regional parliaments find their constituencies. Regional economic policy thus primarily reflects the administrative regions' interests; therefore they are the proper starting points for most purposes of regional economic policy analysis. However, there was no "middle layer" of government between the central state and the municipal level in most new member states of the European Union - so, there was no such tradition. This was also the case in Slovenia (Drobne et al., 2009).

The shortcoming of the Intramax procedure to model too many FRs in a metropolitan area can be observed in Fig. 6, where the metropolitan areas of the two most important employment centres in Slovenia, Ljubljana and Maribor, are fragmented into a number of FRs. On the other hand, most of the rest of Slovenian territory is delimitated into FRs with a similar area. The administrative unit of Ljubljana consists of 10 municipalities that belong to 9 different FRs, and Maribor covers the territory of 6 municipalities that belong to 4 different FRs. The fragmentation of the metropolitan areas of Ljubljana and Maribor is visible even at the level of 12 FRs; see Fig. 5.

As Landre and Håkansson (2013) have already reported for Sweden, this was also the case for Slovenia, i.e. that FRs generated by the Intramax procedure resulted in a fragmented pattern with (unacceptable) low levels of selfcontainment in the metropolitan area. From Fig. 7 it is evident that the two most important employment centres in Slovenia (Ljubljana and Maribor) are surrounded by municipalities/FRs with a very low proportion of intraregional flows and low SSSC and DSSC. DSSC of near

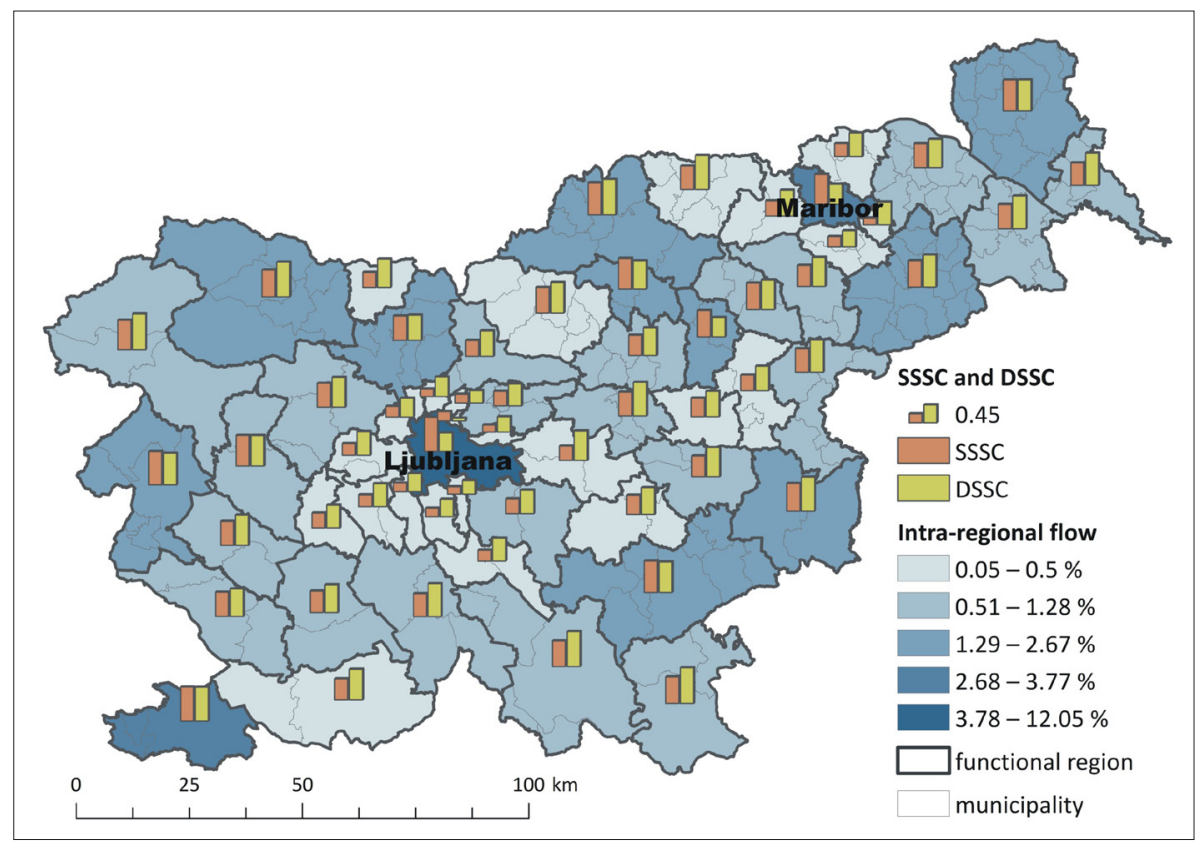

Fig. 7: 58 functional regions modelled by original Intramax procedure (Slovenia, 2011) Source: authors' calculations

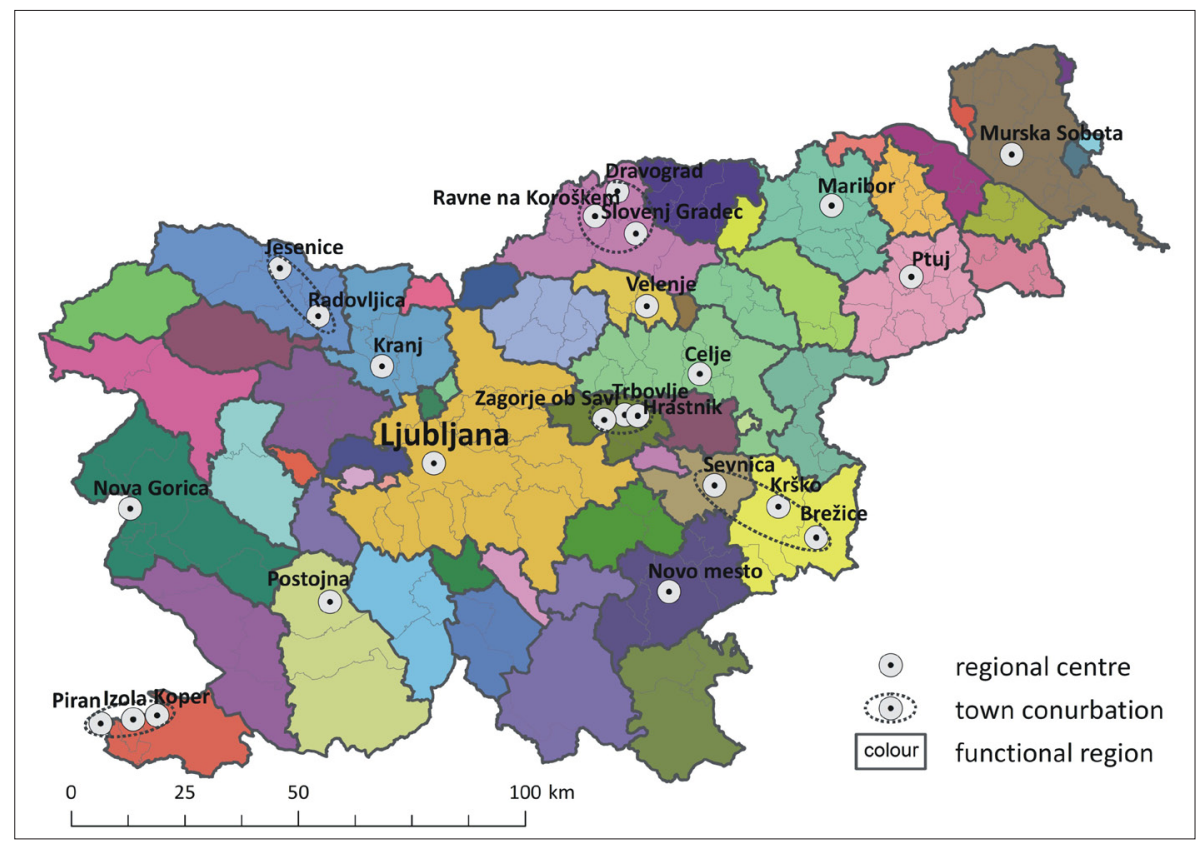

Fig. 8: 58 functional regions modelled using Smart's weighted objective function and 15 regional centres of Slovenia as defined in the Spatial Development Strategy of Slovenia (SDSS, 2004) (Slovenia, 2011)

Source: authors' calculations and SDSS (2004) 
municipalities/FRs is much higher than their SSSC. So, the final result modelled by Intramax procedure could be controlled by additional self-containment criteria to amalgamate BDUs/FRs that do not meet them. In this way, most neighbour municipalities/FRs around Ljubljana and Maribor would be aggregated into two bigger FRs that reflected the functional urban area much more realistically than the delimitation shown in Fig. 7. On the other hand, the problem of fragmented (metropolitan) urban areas can be (partly) solved by using Smart's weighted interaction index $F_{5}$ instead of original Intramax objective function $F_{1}$. Figure 8 shows the result of using objective function $F_{5}$ in the hierarchical aggregation procedure. Here, 58 FRs generated by Smart's weighted interaction index are compared to 15 regional centres in Slovenia that are defined in the Spatial Development Strategy of Slovenia (SDSS, 2004).

\section{Conclusions}

There are many different approaches and methodologies to delineate functional regions (some of which are mentioned in this paper). Intramax is a hierarchical aggregation procedure that tends to delimitate, in its original form (when using the original Intramax objective function), homogeneous FRs regarding intra-regional flows. Variation of intra-regional flows, delimitated by other objective functions analysed herein, is always higher. The tendency to generate FRs with similar intra-regional flows is the reason why the original Intramax function divides metropolitan urban areas into smaller sub-regions (Drobne and Lakner, 2016).

Use of the original Intramax objective function in the hierarchical aggregation procedure operationally delineates the most persuasive regions, but self-containment statistics, and especially the proportion of inner flows, are less acceptable. In general, other objective functions give statistically more persuasive results but operationally less suitable regions. More precisely, if the problem of singleton regions and small isolated FRs were manually corrected, Smart's weighted interaction index (Smart, 1974: see also equation (10) in Tab. 1) would aggregate regions that would be operationally acceptable for the case of Slovenia. Smart's weighted interaction index also generates non-fragmented functional urban areas.

In this case study, we compared functional regions delimitated by the original Intramax procedure to three official delimitations of the Slovenian territory. Two delimitations that are based on long-term analyses of functional interactions, fine-tuned and optimised several times in the past, demonstrate higher self-containment than functional regions. On the other hand, the recent delimitation of Slovenia into two cohesion regions at NUTS 2 level shows lower self-containment than the two functional regions calculated in the original Intramax procedure, using labour commuting inter-municipal interactions.

As already noted, hierarchical aggregation procedures, like Intramax, do not guarantee a global optimal solution to the regionalisation problem. But, the most important advantage of the hierarchical aggregation procedure is its capability to reveal the structure of the grouping process. Masser and Brown (1978: 17) concluded that "the development of special types of hierarchical aggregation procedure is a useful starting point for dealing with the multi-level specification problem. Procedures of this kind have the advantage that they give insights into the structure of the grouping process which can be used to select the desired level of spatial representation and they also give some indication as to the possible configuration of basic data units that occurs at different levels in the grouping process".

From this point of view, the step-by-step use of two or more objective functions in the same aggregation procedure could be an interesting topic for future research. Here, a combination of the original Intramax objective function and Smart's weighted interaction index to avoid the fragmentation of metropolitan areas should be looked into first. On the other hand, and as already noted by Landre and Håkansson (2013), the fragmented pattern of functional regions in metropolitan areas could be improved by the inclusion of the additional self-containment criteria in the whole aggregation procedure or in some of the last aggregation steps. Searching for a new theoretically defined objective function could be another promising research direction. Variations of the objective functions compared in this paper could be analysed, starting with non-symmetric functions $\left(F_{i j} \neq \mathrm{F}_{j i}\right)$, in which different weights could be assigned to origins or destinations.

\section{References:}

ABLER, R., ADAMS, J. S., GOULD, P. (1972): Spatial Organization. London, Prentice-Hall.

ALVANIDES, S., OPENSHAW, S., DUKE-WILLIAMS, 0. (2000): Designing zoning systems for flow data. In: Atkinson, P., Martin, D. [eds]: Innovations in GIS 7, GIS and geocomputation, New York, Taylor and Francis, 115-134.

BALL, R. M. (1980): The use and definition of travel-to-work areas in Great Britain: some problems. Regional Studies, 14(2): 125-139.

BERRY, B. J. L., GARRISON, W. L. (1958): The functional bases of the central place hierarchy. Economic Geography, 34(2): 145-154.

BROWN, P. J. B., HINCKS, S. (2008): A framework for housing market area delineation: Principles and application. Urban Studies, 45(11): 2225-2247.

BROWN, P. J. B., PITFIELD, D. E. (1990): The Intramax derivation of commodity market structures from freight flow data. Transportation Planning and Technology, 15(1): 59-81.

CASADO-DIAZ, J. M. (2000): Local labour market areas in Spain: A case study. Regional Studies, 34(9): 843-856.

CASADO-DIAZ, J. M., COOMBES, M. G. (2011): The delineation of $21^{\text {st }}$ century local labour market areas: a critical review and a research agenda. Boletín de la Asociación de Geógrafos Espańoles, 57: 7-32.

COOMBES, M. G. (2010): Defining labour market areas by analysing commuting data: innovative methods in the 2007 review of Travel-to-Work Areas. In: Stillwell, J., Duke-Williams, O., Dennett, A. [eds.]: Technologies for migration and commuting analysis: Spatial interaction data applications. Hershey, IGI Global, 227-241.

COOMBES, M. G., BOND, S. (2008): Travel-to-Work Areas: the 2007 review. Office for National Statistics, London.

COOMBES, M. G., DIXON, J. S., GODDARD, J. B., OPENSHAW, S., TAYLOR, P. J. (1982): Functional regions for the population census of Great Britain. In: Herbert, D. T., Johnston, R. J. [eds.]: Geography and the Urban Environment. Progress in Research and Applications 5, Chichester, John Wiley and Sons Ltd., 63-112. 
COOMBES, M. G., GREEN, A. E., OPENSHAW, S. (1986): An efficient algorithm to generate official statistical reporting areas: The case of the 1984 travel-to-workareas revision in Britain. Journal of the Operational Research Society, 37(10): 943-953.

CÖRVERS, F., HENSEN, M., BONGAERTS, D. (2009): Delimitation and coherence of functional and administrative regions. Regional Studies, 43(1): 19-31.

DARAS, K. (2005): An information statistics approach to zone design in the geography of health outcomes and provision. PhD dissertation, University of Newcastle. Newcastle, United Kingdom.

DE JONG, T., VAN DER VAART, N. (2013): Manual Flowmap 7.4.2, Faculty of Geographical Sciences, Utrecht University, The Netherlands. [online]. [cit. 14.08.2015]. Available at: < http://flowmap.geo.uu.nl/ downloads/FM742_Manual.pdf $>$

DROBNE, S., BOGATAJ, M. (2012a): A method to define the number of functional regions: An application to NUTS 2 and NUTS 3 levels in Slovenia = Metoda opredelitve števila funkcionalnih regij: Aplikacija na ravneh NUTS 2 in NUTS 3 v Sloveniji. Geodetski vestnik, 56(1): 105-150.

DROBNE, S., BOGATAJ, M. (2012b): Evaluating functional regions. In: Babić, Z. et al. [eds]: $14^{\text {th }}$ International conference on operational research, Trogir, Croatia, September 26-28, 2012, Croatian operational research review, 3: 14-26. [online]. [cit. 10.08.2015]. Available at: $<$ hrcak.srce.hr/file/142254>

DROBNE, S., BOGATAJ, M. (2014): Regions for servicing old people: Case study of Slovenia. Business systems research journal, 5(3): 19-36.

DROBNE, S., BOGATAJ, M. (2015): Optimal allocation of public service centres in the central places of functional regions. In: $15^{\text {th }}$ IFAC/IEEE/IFIP/IFORS Symposium on Information Control Problems in Manufacturing, INCOM 2015. Ottawa, IFAC, 2449-2454.

DROBNE, S., LAKNER, M. (2015): Intramax and constraints. In: Zadnik-Stirn, L., Žerovnik, J., Kljajić Borštner, M., Drobne, S. [eds.]: The $13^{\text {th }}$ International Symposium on Operations Research in Slovenia, SOR '15. Bled, SDISOR, 433-438.

DROBNE, S., LAKNER, M. (2016): Use of constraints in the hierarchical aggregation procedure Intramax. Business Systems Research Journal, 7 (in print).

DROBNE, S., LISEC, A., KONJAR, M., ZAVODNIK LAMOVŠEK, A., POGAČNIK, A. (2009): Functional vs. Administrative regions: Case of Slovenia. In: Vujošević, M., Perić, J. [eds.]: International Scientific Conference Regional Development, Spatial Planning and Strategic Governance: Thematic Conference Proceedings, Belgrade, 395-416.

FARMER， C. J. Q., FOTHERINGHAM， A. S. (2011): Network-based functional regions. Environment and Planning A, 43(11): 2723-2741.

FELDMAN, O., SIMMONDS, D. C., TROLL, N., TSANG, F. (2005): Creation of a system of functional areas for England and Wales and for Scotland. European Transport Conference, Strasbourg (on CD), PTRC, London. [online]. [cit. 06.08.2015]. Available at: <http:// www.davidsimmonds.com/files/resourcesmodule/@ random4767836fd9d18/1200086162_ETC_2005_ Feldman_et_al.pdf >
FENG, Z. (2009): Fuzziness of Travel to Work Areas. Regional Studies, 43(5): 707-720.

FISCHER, M. M., ESSLETZBICHLER, J., GASSLER, H., TRICHTL, G. (1993): Telephone communication patterns in Austria - A comparison of the IPFP-based graphtheoretic and the Intramax approaches. Geographical Analysis, 25(3): 224-233.

GOETGELUK, R., DE JONG, T. (2007): What about the spatial dimension of subsidiarity in housing policy? ENHR 2007 International conference on Sustainable Urban Areas. ENHR, Rotterdam. [online]. [cit. 06.08.2015]. Available at: < https://www.yumpu.com/ en/document/view/26672955/what-about-the-spatialdimension-of-subsidiarity-in-housing-policy>

GREGORY, D., JOHNSTON, R. J., PRATT, G., WATTS, M., WHATMORE, S. [eds.] (2009): The Dictionary of Human Geography, $5^{\text {th }}$ edition. Oxford, Wiley-Blackwell.

HIRST, M. A. (1977): Hierarchical aggregation procedures for interaction data: A comment. Environment and Planning A, 9(1): 99-103.

JAEGAL, Y. (2013): Delineating housing market areas in the Seoul metropolitan area using a geo-computational approach. Journal of the Association of Korean Geographers, 2(1): 7-20.

KARLSSON, C., OLSSON, M. (2006): The identification of functional regions: theory, methods, and applications. The Annals of Regional Science, 40(1): 1-18.

KIM, H., CHUN, Y., KIM, K. (2015): Delimitation of functional regions using a p-regions problem approach. International Regional Science Review, 38(3): 235-263.

KILLIAN, M. S., TOLBERT, C. M. (1993): Mapping social and economic space: the delineation of local labour markets in the United States. In: Singelmann, J., Desaran, F. A. [eds.]: Inequalities in Labour Market Areas. Boulder, Westview, 69-79.

KLAPKA, P., HALÁS, M., TONEV, P. (2013): Functional regions: Concept and types. In: $16^{\text {th }}$ International Colloquium on Regional Sciences, Conference Proceedings. Brno, Masaryk University, 94-101.

KOHL, T., BROUVER, A. E. (2014): The development of trade blocs in an era of globalisation. Environment and Planning A, 46(7): 1535-1553.

KOO, H. (2012): Improved hierarchical aggregation methods for functional regionalization in the Seoul metropolitan area. Journal of the Korean Cartographic Association, 12(2): 25-35.

KRYGSMAN, S., DE JONG, T., NEL, J. (2009): Functional transport regions in South Africa: An examination of national commuter data. Proceedings of the $28^{\text {th }}$ South African transport conference. Pretoria, South Africa, 144-154. [online]. [cit. 06.08.2015]. Available at: < http://repository.up.ac.za/bitstream/handle/2263/11952/ Krygsman_Functional\%282009\%29.pdf>

LANDRÉ, M., HÅKANSSON, J. (2013): Rule versus Interaction function: evaluating regional aggregations of commuting flows in Sweden. European Journal of Transport and Infrastructure Research, 13(1): 1-19.

MASSER, I., BROWN, P. J. B. (1975): Hierarchical aggregation procedures for interaction data. Environment and Planning A, 7(5), 509-523. 
MASSER, I., BROWN, P. J. B. (1977): Spatial representation and spatial interaction. Papers of the Regional Science Association, 38(1): 71-92.

MASSER, I., BROWN, P. J. B. (1978): Spatial representation and spatial interaction: an overview. In: Masser, I. and Brown, P. J. B. [eds]: Spatial representation and spatial interaction. Studies in applied regional science, Leiden and Boston, Martinus Nijhoff Social Sciences Division, 1-23.

MASSER, I., SCHEURWATER, J. (1978): The specification of multi-level systems for spatial analysis. In: Masser, I. and Brown, P.J. B. [eds]: Spatial representation and spatial interaction. Studies in applied regional science, Leiden and Boston, Martinus Nijhoff Social Sciences Division, 151-172.

MASSER, I., SCHEURWATER, J. (1980): Functional regionalisation of spatial interaction data: An evaluation of some suggested strategies. Environment and Planning A, 12(12): 1357-1382.

MITCHELL, W., BAUM, S., FLANAGAN, M., HANNAN, M. (2013): CofFEE functional economic regions. AURIN project. Centre of Full Employment and Equity. Darwin, Australia. [online]. [cit. 06.08.2015]. Available at: < http://e1.newcastle.edu.au/coffee/functional_regions/>

MITCHELL, W., BILL, A., WATTS, M. (2007): Identifying functional regions in Australia using hierarchical aggregation techniques. Centre of Full Employment and Equity. Working Paper No. 07-06. Newcastle, Australia. [online]. [cit. 06.08.2015]. Available at: < http:// e1.newcastle.edu.au/coffee/pubs/wp/2007/07-06.pdf>

MITCHELL, W., STIMSON, R. (2010): Creating a new geography of functional economic regions to analyse aspects of labour market performance in Australia. In: Dalziel, P. [ed.]: Innovation and regions: Theory, practice and policy. Lincoln, New Zealand, AERU Research Unit, 178-220.

MITCHELL, W., WATTS, M. (2010): Identifying functional regions in Australia using hierarchical aggregation techniques. Geographical Research, 48(1): 24-41.

NEL, J. H., KRYGSMANY, S. C., DE JONG, T. (2008): The identification of possible future provincial boundaries for South Africa based on an Intramax analysis of journeyto-work data. Orion, 24(2): 131-156.

OECD (2002): Redefining territories: the functional regions. Paris, OECD.

ONS, COOMBES, M. G. (1998): 1991-based Travel-to-Work Areas. Office for National Statistics, London.

OPENSHAW, S., ALVANIDES, S. (1999): Applying geocomputation to the analysis of spatial distributions. In: Longley, P. A., Goodchild, M. F., Maguire, D. J., Rhind, D. W. [eds.]: Geographical Information Systems: Principles, Techniques, Applications and Management, Chichester, Wiley, 1: 267-282.
OPENSHAW, S., RAO, L. (1995): Algorithms for reengineering 1991 census geography. Environment and Planning A, 27(3): 425-446.

OPENSHAW, S., WYMER, C. (1995): Classifying and regionalizing census data. In: Openshaw, S. [ed.]: Census Users Handbook. Cambridge, United Kingdom, GeoInformation International, 239-270.

POON, J. P. (1997): The cosmopolitanization of trade regions: Global trends and implications, 1965-1990. Economic Geography, 73(4): 390-404.

SLATER, P. B. (1981): Comparisons of aggregation procedures for interaction data: An illustration using a college student international flow table. Socio-Economic Planning Sciences, 15(1): 1-8.

SMART, M.W. (1974): Labour market areas: uses and definition. Progress in Planning, 2(4): 239-353.

SORS (2016): Explanations of territorial changes of statistical region, Statistical Office of the Republic of Slovenia, Ljubljana [online]. [cit. 06.08.2015]. Available at: http://www.stat.si/dokument/8486/Explanationsterritorial-changes-statistical-regions.pdf.

SDSS (2004): Spatial development strategy of Slovenia, Ministry of the Environment, Spatial Planning and Energy, Ljubljana [online]. [cit. 06.08.2015]. Available at: http://www.mop.gov.si/fileadmin/mop.gov.si/pageuploads/ publikacije/drugo/en/sprs_eng.pdf; retrieved 25 February 2016.

STATISTICS SWEDEN (2010): Construction and use of labour market areas in Sweden, Enterprise and Registerbased Employment Statistics Unit, Örebro [online]. [cit. 06.08.2015]. Available at: http://www.scb.se/statistik/ publikationer/AM0207 2009A01_BR AM95BR1001.pdf; retrieved 23 January 2012 .

TYREE, A. (1973): Mobility ratios and association in mobility tables. Population Studies, 27(3): 577-588.

ULLMAN, E. L. (1980): Geography as spatial interaction. Seattle and London: University of Washington Press.

VAN DER LAAN, L., SCHALKE, R. (2001): Reality versus policy: the delineation and testing of local labour market and spatial policy areas. European Planning Studies, 9(2): 201-221.

VANHOVE, N., KLAASSEN, L. H. (1987): Regional policy: a European approach, $2^{\text {nd }}$ edition. Avebury, Gower Publishing Company Limited, Aldershot.

WARD, J. H. (1963): Hierarchical grouping to optimize an objective function. Journal of the American Statistical Association, 58(301): 236-244.

WATTS, M. (2009): Rules versus hierarchy: An application of fuzzy set theory to the assessment of spatial grouping techniques. In: Kolehmainen, M. et al. [eds.]: Adaptive and naturals computing algorithms. Berlin Heidelberg, Springer-Verlag, 517-526.

\section{Please cite this article as:}

DROBNE, S., LAKNER, M. (2016): Intramax and other objective functions: The case of Slovenia. Moravian Geographical Reports, 24(2): 12-25. Doi: 10.1515/mgr-2016-0007. 